\title{
Re-Conceptualizing School Continuation \& Re-Entry Policy for Young Mothers Living in an Urban Slum Context in Nairobi, Kenya: A Participatory Approach
}

\author{
MILKA PEREZ NYARIRO \\ McGill University, Canada
}

\begin{abstract}
This article discusses the barriers to school continuation for pregnant girls and young mothers living in low-income and marginalized contexts in Nairobi, Kenya. In the article, I suggest adopting a girl-centered framework in the policy formulation process (Moletsane, Mitchell, \& Lewin, 2015). This perspective puts girls' voices at the center of the policy formulation process to help address the persistent gender inequality in education through problem identification and an exploration of ways to combat the challenges faced by girls. The article, which analyzes studies of government's education policies, is supported by data from my recent fieldwork investigating young mothers' challenges to school continuation and re-entry in Kenya, within the context of Kenya's re-entry and continuation policy effected in 1994. I discuss the school re-entry and continuation policies in low-income contexts using the framework of critical feminism. I argue that there is need to integrate multi-pronged, participatory and feminist frameworks to promote systematic government educational policy reforms to shore up gender equality (King \& Winthrop, 2015). To support this argument, I develop three main claims: (a) broad conceptualization of the causes of teenage pregnancy will promote the use of multipronged approaches to the design of school re-entry and continuation policies; (b) formulation and implementation of any robust policies on re-entry and continuation require strong integration of the voices, perspectives and the lived experiences of pregnant teenage girls and young mothers; and (c) the use of participatory visual methodologies will give voice to pregnant girls and young mothers, and promote policy dialogue while at the same time empowering them and spurring their agency to become part of policy formulation and implementation.
\end{abstract}

KEYWORDS gender; education; social policy; marginalization; participatory; feminism; intersectionality; sub-Saharan Africa 


\section{Introduction}

This article is part of a special issue of Studies in Social Justice that commemorates and advances the work and legacy of Jacqueline Kirk who was killed in an attack by the Taliban in Afghanistan on August 13, 2008, alongside two other colleagues and a driver. The commitment Kirk displayed to social justice, youth and girlhood studies, gender equality and inclusion in education, remains urgent. The objectives of this article align with her advocacy for the rights of children, particularly girls, to participate in decision-making processes, as well as her contributions to policy development. Kirk's contributions to gender equality in education include advocating for the use of visual and other participatory methodologies as a way to support the agency of adolescent girls in marginalized contexts, and amplifying marginalized children's voices through images to talk about issues of education and well-being and as a safe strategy to break barriers of autocracy in policy formulation. Her realization and that of other scholars in the field of gender equality and social justice that the conventional top-down approach of policy-making process may risk perpetuating existing power dynamics between policy makers and policy beneficiaries has led to the use of creative, multi-pronged and feminist approaches such as Participatory Visual Methodologies which prioritize women's voices in policy and decision making. Despite the continued efforts to democratize decision and policy-making processes, girls' and women's voices continue to be marginalized, sometimes with only a few of them enlisted to contribute. This article outlines the challenges to school continuation faced by young mothers living in urban low-income conditions within the context of Kenya's 1994 school re-entry and continuation policy. The article offers (a) some data that could be useful in the policy formulation process, and (b) a technique that could be used in the policy formulation process to integrate the voices and interests of girls.

I have divided the article into four sections. In the first section, I highlight the broader conversation about girls' and women's education in sub-Saharan Africa to provide a theoretical framework for the article. The second section provides an overview of teenage pregnancy and schooling in sub-Saharan Africa (SSA). In section three, I review studies on continuation and re-entry policies for young mothers in selected countries in SSA and the challenges of the existing policies. The section also reports the findings from a participatory study with pregnant girls and young mothers in an urban slum in Nairobi, Kenya. The objective of the study was to explore challenges to school continuation for pregnant girls and young mothers. The final section draws from the literature and findings of my study to propose ways policy makers could draw from photovoice - a participatory approach - to reconceptualize school continuation and re-entry policies for young mothers. I offer recommendations for girl-centered and participatory approaches as inclusive ways of policy-making. 
To ensure clarity, I will begin by defining some of the terms used in this article. I use UNESCO's (2003) conceptualization of "gender equality" as placing equal value on the similarities and differences between men and women, and the roles they play in society. Gender equality, conceived this way, means that women and men are given equal conditions for realizing their full human rights and for contributing to, and benefiting from, economic, social, cultural and political development. I adopt the definition of policy design by Bobrow and Dryzek (1987, cited in Rixecker, 1994, p. 119) as "the process of creating, developing and attuning an actionable framework, incorporating heightened context sensitivity and value clarification with the intent of ameliorating some social issues." I use teenage and adolescent interchangeably in this article to represent young people between the ages of 13 and 19 years. Similarly, I use pregnant girls and young mothers interchangeably to represent girls between the ages of 13 and 19 years who become pregnant while attending school. I argue that there is a need to integrate feminist frameworks to promote systematic government educational policy reforms and evaluation to shore up gender equality (King \& Winthrop, 2015) and make three supporting claims. First, a broad conceptualization about the causes of teenage pregnancy will promote the use of multi-pronged approaches to the design of school continuation and re-entry policies. Second, formulation and implementation of any robust policies on re-entry and continuation require strong integration of voices, perspectives, and lived experiences of pregnant teenage girls and young mothers. Third, the use of participatory visual methodologies will give voice to the pregnant girls and young mothers and promote policy dialogue. This will empower them and spur their agency to become part of policy formulation and implementation conversations.

\section{Girls' Education in Sub-Saharan Africa}

Girls' education is perceived as an investment in human capital that promotes economic growth and increases a country's human development and well-being (King \& Winthrop, 2015; Lockheed, 2008; Schultz, 2002). The literature shows that the social benefits of more years of schooling are greater for girls than boys. For instance, regions that have invested in girls' and women's schooling have relatively fast-tracked in development due to improved women's participation and contribution to economic and social development (King \& Winthrop, 2015; Schultz, 2002). Scholarly literature also provides a plethora of evidence showing the benefits of female education. For example, when women attain more years of education, countries experience improvements in human capital, maternal health, fertility, family planning and agricultural production (King \& Winthrop, 2015; Lockheed, 2008). 
Although there have been significant gains in advocacy and strategies for girls' education in general, gaps persist for adolescent girls, and especially young mothers living in marginalized contexts (King \& Winthrop, 2015). A complex and layered intersection of socio-cultural and socioeconomic factors works to produce and reproduce gender inequality that leads to many girls getting pregnant and dropping out of school in SSA. Scholars like Mukudi (2002) and Stromquist (2003) outline the intersectional nature of challenges, such as poverty, cultural dispositions, and government policies, among other factors. These factors work together to pose barriers to adolescent girls' schooling, exacerbating the marginalization of girls and young women in education. To effectively address the layers and intersections of these challenges, it is important to include the voices of the girls themselves. By drawing insights from their lived experiences, it is possible to gain a nuanced understanding of their problems, in order to develop effective mitigation strategies.

\section{Teenage Pregnancy, Motherhood and Schooling in Sub-Saharan Africa}

Teenage pregnancy has been identified as a factor that contributes significantly to girls dropping out of school before completing a full cycle of basic education, thereby leading to a persistent gender inequality gap in education (Bhana \& Mcambi, 2013; Onyango, Kioli, \& Nyambedha, 2015; Sathiparsad \& Taylor, 2011). An adolescent girl's unplanned pregnancy is often the result of gender power imbalances, hierarchical social power relations, and sexual inequality between men and women (Sathiparsad \& Taylor, 2011). Available data shows that pregnancy accounted for $13.9 \%$ of teenage girls who were not in schools in South Africa in 2006. A study conducted by the Population Council in Kenya (see Undie, Birungi, Odwe, \& Obare, 2015a) shows that $21 \%$ of adolescent girls reported having been pregnant and dropping out of school. This study revealed further that the majority of girls who became pregnant and dropped out of school did not reenter due to the stigma and ridicule associated with pregnancy, both in school and in the wider community. The study also indicated that re-entry and continuation policy guidelines were not implemented in most schools, and that a suitable framework to monitor and evaluate the implementation and progress of the policy was lacking. Another study from South Africa offers additional findings regarding the implementation of the South African School Act (SASA) (Republic of South Africa, 1996), an act that makes it illegal to exclude pregnant girls from schools. The study shows that about $32 \%$ of 14 19 years old school going girls who had ever become pregnant have reentered school because of the presence of the SASA (Bhana, Morrel, Shefer, $\&$ Ngabaza, 2010). However, the Act does not clearly specify the treatment of pregnant learners and learner-parents while in school. 
Teenage pregnancy continues to be one of the major challenges to the achievement of Education for All (EFA) (Leach, Dunne, \& Salvi, 2014; Onyango et al., 2015). It causes and maintains a difference in transition rates between male and female students. School transition and completion rates among girls dwindle due to several factors including teenage pregnancy and motherhood (FAWE, 2004). Differential gender power relations are a major cause of teenage pregnancy and motherhood. The gender power asymmetry constrains young women's sexual choices and ability to negotiate safe sex. Social construction of sex and sexuality, which depicts female sexuality as subdued yet applauds male sexual dominance, contributes to these constraints and consequently encourages girls to succumb to male pressure (Arango, Morton, Gennari, Kiplesund, \& Ellsberg, 2014; Leach et al., 2014). Adolescent girls' lack of access to sexuality education, limited ability to negotiate sexual relationships, and restricted access to reproductive health information and services all contribute to teenage pregnancy and early motherhood (Leach et al., 2014).

The challenge that most communities, schools, education ministries and governments continue to grapple with is how to integrate young mothers into the schooling systems (Arango et al., 2014; Bhana et al., 2010; Onyango et al., 2015; Undie et al., 2015a). Many national governments in SSA have adopted global initiatives on gender equality and have targeted policies supporting girls and women, particularly in education (Glick, 2008). However, many of these countries continue to grapple with effective ways to include young mothers in the mainstream educational and schooling systems, as many girls - particularly in SSA - continue to withdraw from school due to teenage pregnancy (Bhana \& Mcambi, 2013; Undie et al., 2015a).

In many societies in SSA, teenage pregnancy and motherhood are perceived to be incompatible with schooling. Studies outline ways historical and contemporary moral, cultural and social norms combine to construct and pathologize teenage pregnancy and motherhood outside of marital family contexts (Bhana, et al., 2010; Moletsane, Mitchell, \& Lewin, 2015). The agency of pregnant girls and young mothers continues to be suppressed as teenage pregnancy and motherhood is socially constructed as unacceptable, shameful and punishable in popular and everyday discourses (Bhana \& Mcambi, 2013). For instance, a study by Bhana et al. (2010), which explored teachers' responses to teenage pregnancy and parenting in South Africa, revealed that most school principals and teachers reproduce gender violence and inequality by not being ready to admit and support pregnant learners or mothers in their schools, the presence of the policy notwithstanding. Similarly, studies by Beninger (2013), Undie et al. (2015a), and Vandayar, Dzimiri, Runhare, \& Mulaudzi (2014), show that although school authorities express concern about the welfare of pregnant learners and young mothers, they nevertheless view teenage pregnancy as stigmatizing and these girls as poor role models for the school. Such attitudes create an exclusionary and unwelcoming school environment that marginalizes young mothers. 
Furthermore, studies reveal that young mothers who go back to school encounter challenges, and lack support from fellow students and teachers. This hinders their ability to accomplish their educational goals (Bhana \& Mcambi, 2013; Moletsane et al., 2015; Onyango et al., 2015). Young mothers in schools are subject to the school's rules, regulations and policies, which can reproduce discrimination, marginalization and social injustice towards the girls. Moreover, teenage pregnancy and motherhood are not condoned by schools due to society's disapproval of open displays of teenage sexuality.

\section{School Continuation \& Re-Entry Policies in Sub-Saharan Africa}

Efforts to promote school continuation and re-entry policies for young mothers in SSA are complicated by the existence of divergent policy implementation. Some policies (e.g., Tanzania's) deny pregnant girls and young mothers the opportunities to continue or re-enter schools. Others are unclear in ways that make it difficult for girls and young women to know their rights. In Kenya, Zambia and South Africa, for example, existing policies are poorly-implemented. Only in rare cases do clearly-formulated policies correspond with effective implementation (e.g., Botswana) (Chilisa, 2002). Mashishi and Makoelle (2014) divide the policies on learner pregnancy into three categories: (a) expulsion policies which symbolize direct violation of girls' fundamental human rights; (b) re-entry policies, which allows pregnant girls to come back to school after giving birth; and (3) continuation policies, which allow pregnant girls to continue at school until the time of their babies' birth. The authors point out that school continuation and re-entry policies are common in countries that have ratified the Convention on the Elimination of all Forms of Discrimination against Women and the Conventions on the Rights of Children (CEDAW). Mashishi and Makoelle $(2014$, p. 377) further note that re-entry policies subtly violate girls' right to education through a "retreat ideology," a situation where school authorities suggest to pregnant girls and young mothers that an option for continued schooling includes voluntarily withdrawing from school with the option to return after they give birth. However, in many cases, girls who opt for voluntary withdrawal from school do not return.

The current policy frameworks on learner pregnancy in most countries in SSA are silent on services for learner mothers and on how young mothers might care for their newly born child. A major challenge for young mothers, their families, and communities, is how to balance conflicting demands of childcare and schooling (Moletsane et al., 2015). Due to lack of clear guidelines on how to accommodate young mothers, schools can be a hostile environment with punitive measures for young mothers who fail to accomplish their homework or follow in schools' structured routines (Bhana, 2008; Bhana et al., 2010; Bhana \& Mcambi, 2013; Moletsane et al., 2015). 
In Kenya, every individual has a right to an education (Constitution of Kenya, 2010). The re-entry policy to help young mothers return to schools came into law in 1994 (Undie et al., 2015a). According to the Kenya 2009 Demographic Health Survey (Onyango et al., 2015), 18\% of girls have experienced a pregnancy by the age of 18 years, making it one of the major causes for teenage girls dropping out of school. Studies also reveal that most of the girls who drop out of school due to early pregnancy do not resume school after childbirth despite the policy's provision for it (Onyango et al., 2015; Undie et al., 2015a; Undie et al., 2015b). In Kenya, it is estimated that between 10,000 and 13,000 girls drop out of school annually due to pregnancy, but approximately only 1,200 return after giving birth (Onyango et al., 2015). Despite the school re-entry policy in Kenya having clauses of unconditional readmission for young mothers, it was evident at a meeting organized by the STEP UP and Population Council with school principals in Homa Bay county to have a dialogue on the re-entry and continuation policy, that many school principals thought young mothers should only be readmitted if they showed remorse for becoming pregnant (Undie et al., 2015b). This provides evidence that the mere existence of a re-entry policy does not translate into accessible schooling for young mothers.

\section{Researching the Challenges to Young Mothers' School Continuation}

Over the past two years, I have been investigating the challenges faced by pregnant teenagers and young mothers in informal urban settlements in and around Nairobi as they seek to re-enter school to complete their education. The study employs the participatory visual approach of photovoice to provide agency and voice for pregnant teenagers and young mothers in the policy discourse (Nyariro, Muthuri, Hani Sadati, Mitchell, \& Njeri, 2017; Mitchell, 2011). Fifteen young mothers and pregnant teenagers between the ages of 13 and 19 years and living in Korogocho, one of the largest slums in Kenya, participated in the photovoice project in August 2017. Photovoice, a qualitative visual research methodology, relies on the use of cameras by participants to explore stories, experiences, or ideas about a social issue. Participants underwent training in photography and visual ethics, adhering to a "no faces" (Mitchell, 2011) approach in taking photos for research purposes. Following the training, participants (girls and young mothers) went into the community in groups of four or five to take photos that corresponded with the research question, and which were guided by a photovoice prompt: "What are your challenges as pregnant girls and young mothers in this community?" The participants took over 100 pictures in total. Each one chose three to four of their photos, which they judged as best representing the issues, and wrote captions for each photo to further explain the meaning that the photos had for them. They created four photo narratives based on the 
selected photos, identified the common themes, and presented their findings to the community.

Although the study is ongoing, three major themes emerged from the initial photovoice activity: (a) the absence of clean and affordable daycares, (b) lack of supportive and safe social and physical environments, and (c) poverty. The photos taken by the girls and young mothers to highlight absence of clean and affordable daycares include one featuring a young mother helping in a family business with her child on her back (Figure 2). This picture signifies how young mothers have to attend to other roles and childcare. Such situations make it impossible for them to combine those roles with childcare and demands of schooling. Another photo (Figure 6) depicts a ramshackle metal building that says "baby care" and has a contact telephone number written on the door, to show the inadequate state of most available daycare facilities within the community. In contrast to this, an additional photo (Figure 11) showed a concrete block building in a fairly clean environment; the caption explains that young mothers lack finances to afford such clean and reliable daycares. Pictures and captions that highlight the lack of supportive social and physical environment include one showing young girls sitting and walking unattended by the roadside (Figure 5). Another showed community members sitting by the roadside and gossiping about pregnant girls (Figure 8). A photo of a group of young men sitting idly by the roadside was featured to illustrate the state of hopelessness in the community and inability of young men who impregnate young girls to support them with childcare (Figure 10). Photos relating to poverty include one of young mothers looking for used plastic and metal at the dumpsite to resell for an income (Figure 9), and another of a young mother walking in a business area looking for a job (Figure 7). Another photo showed young mothers washing used sacks for recycling and resale in a dirty river (Figure 4), and young mothers engaging in the businesses of hand-washing clothes to generate income, instead of going back to school (Figure 1).

The three themes identified by young mothers - the absence of clean and reliable daycares, lack of supportive social and physical environment, and poverty - create multiple factors that pose barriers to school continuation and re-entry for young mothers living in urban slum contexts. Education sectors therefore need to adopt feminist and multi-pronged approaches to break these barriers to make education accessible to young mothers. This entails prioritizing women's voices through participatory and creative techniques such as photovoice. 


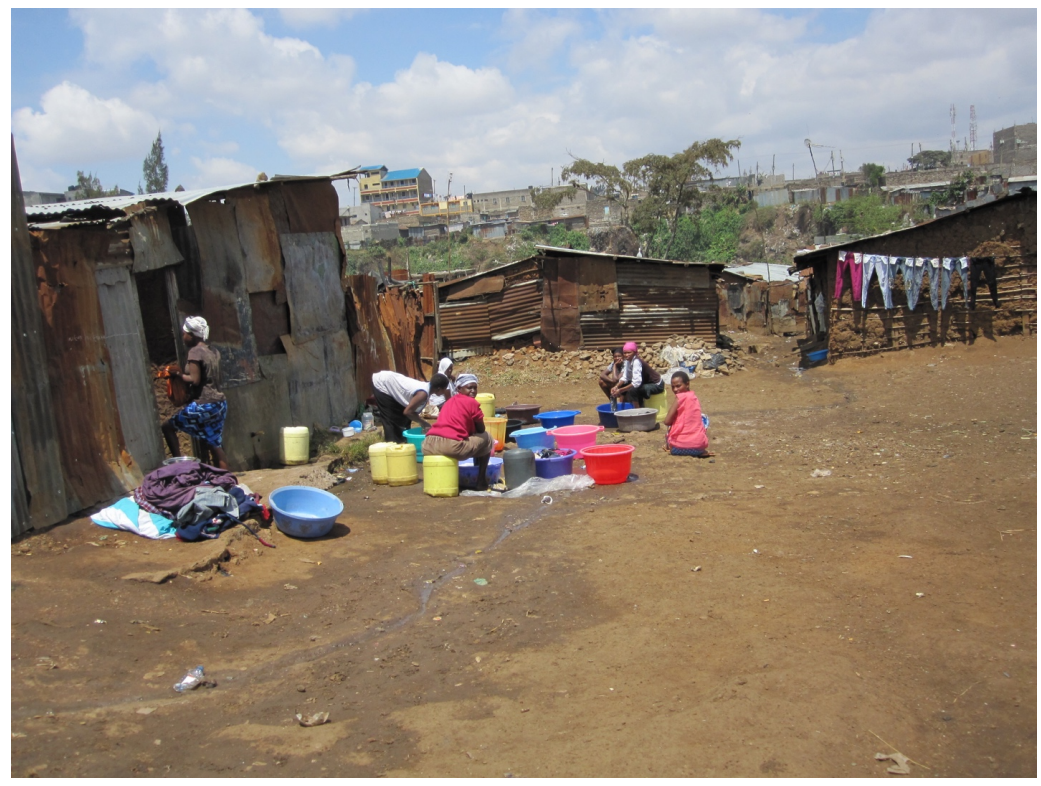

Figure 1. Young mothers hand-washing clothes to earn an income. ${ }^{1}$

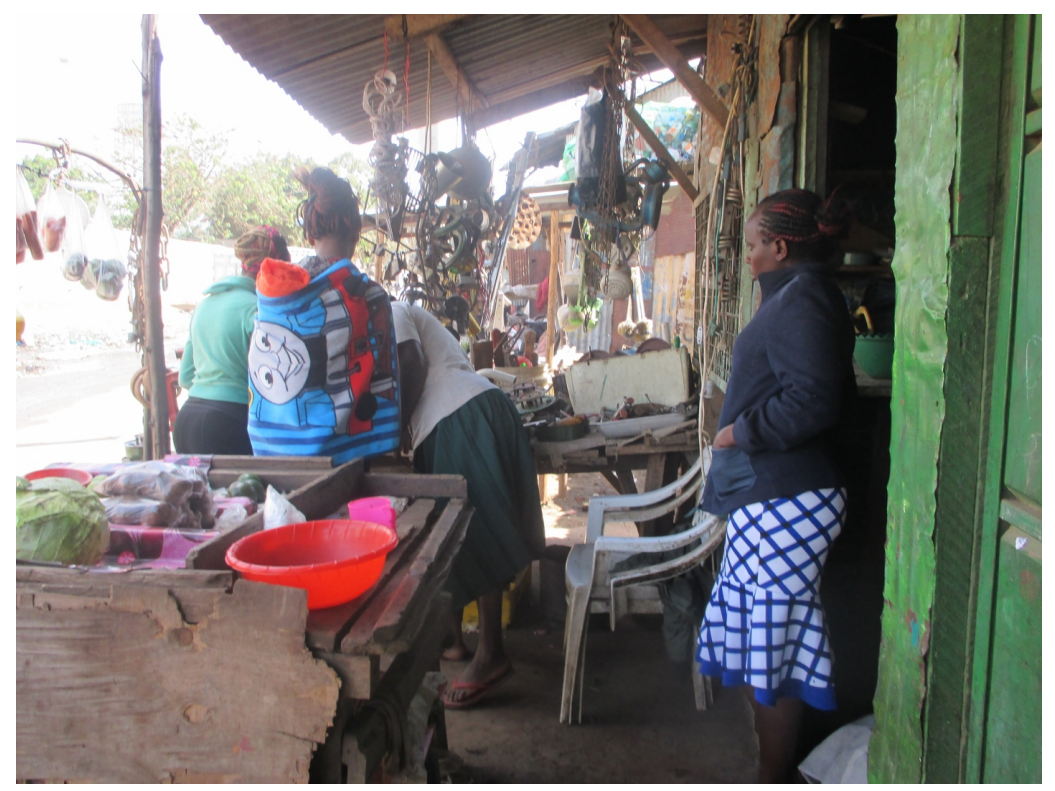

Figure 2. A young mother helping out in the family business with her child on her back.

${ }^{1}$ All images were produced and captioned by young mothers participating in the study.

Studies in Social Justice, Volume 12, Issue 2, 310-328, 2018 


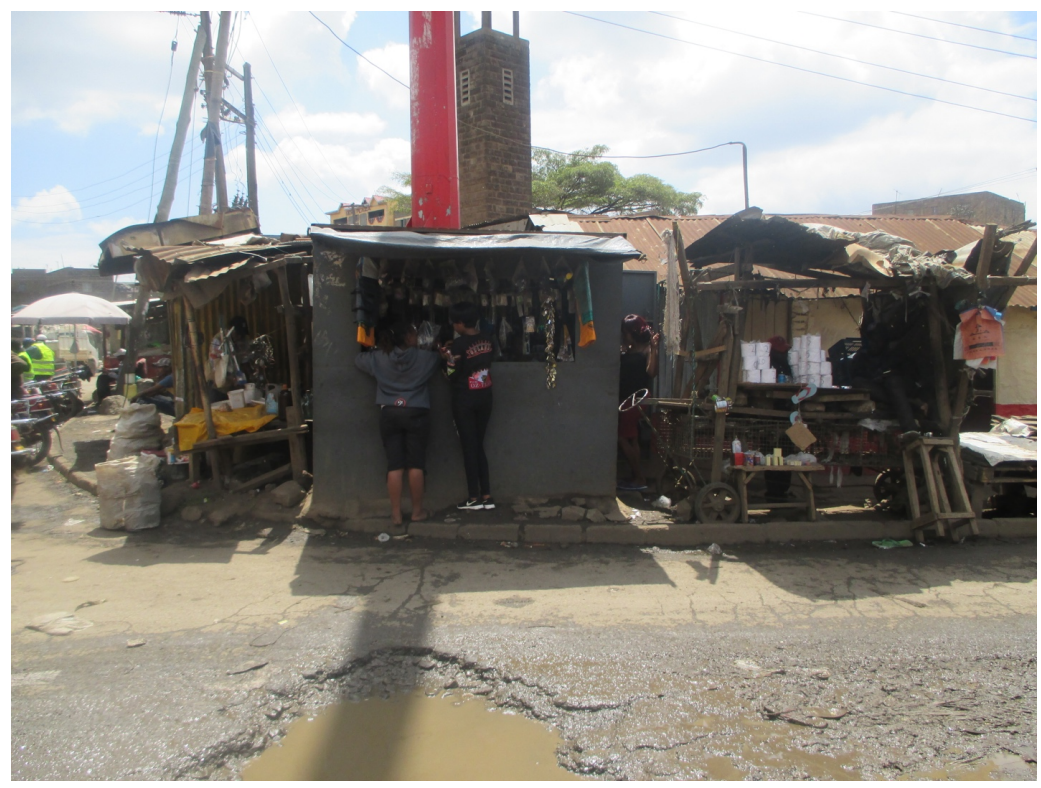

Figure 3. Male business owners lure young girls into sexual relations in exchange for money and gifts.

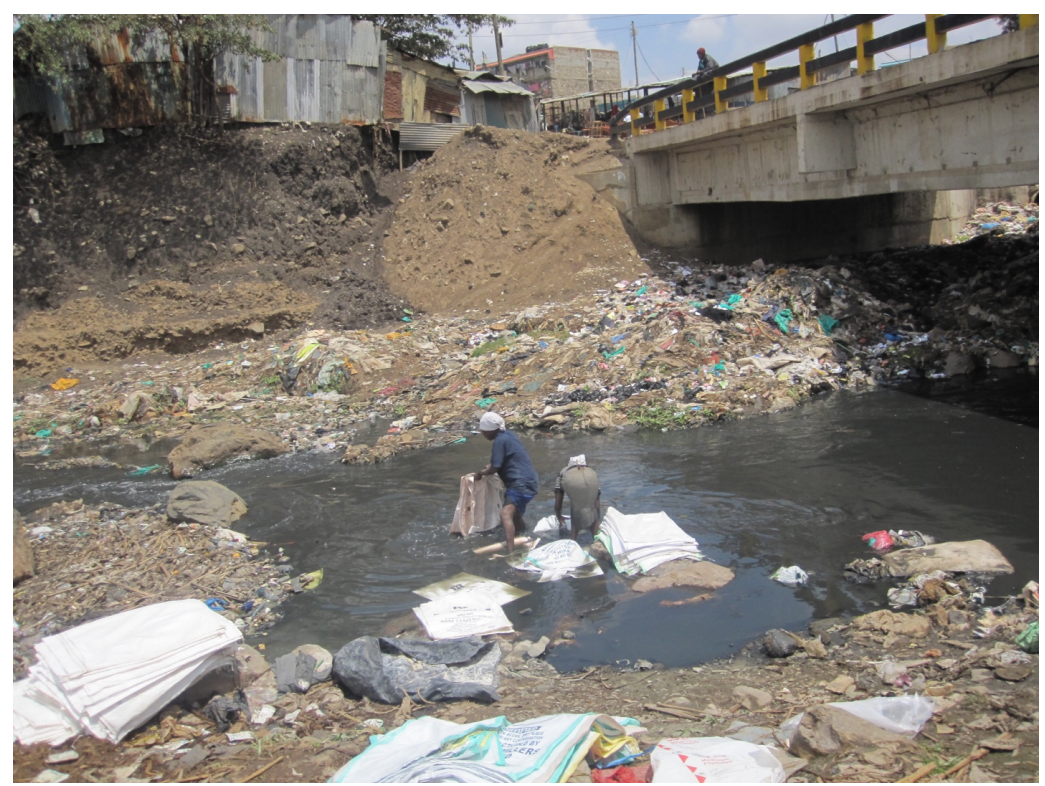

Figure 4. Young mothers washing used sacks in a dirty river for recycling and resale. 


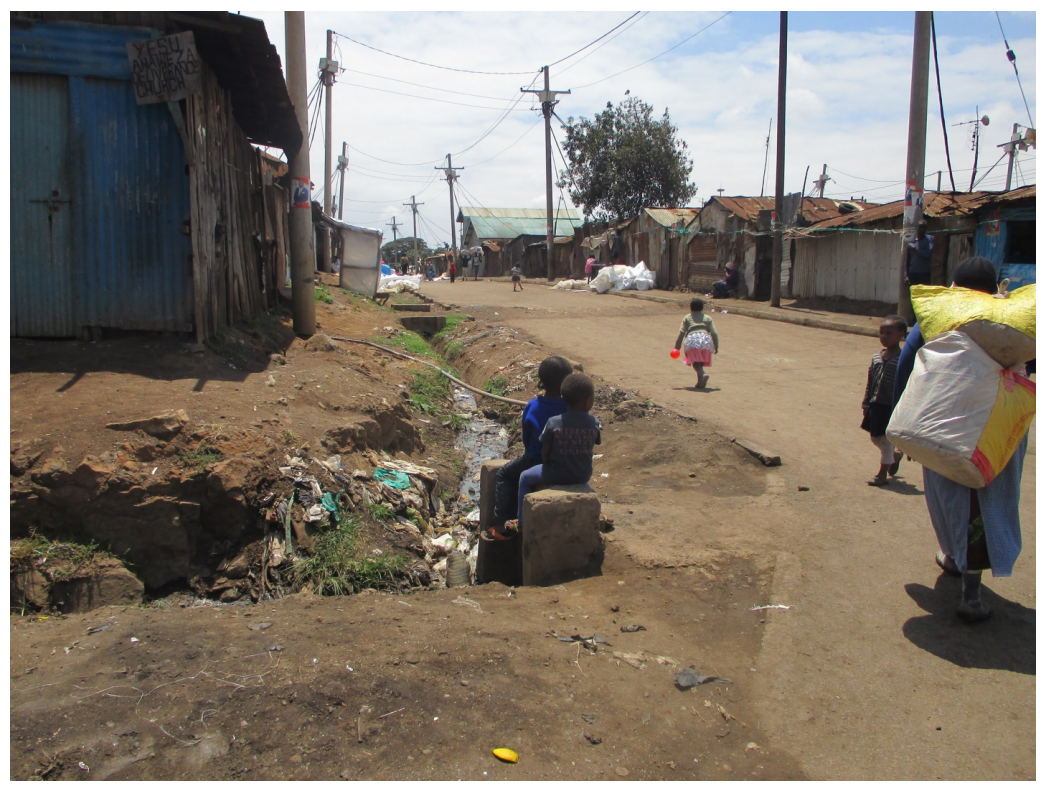

Figure 5. Irresponsible upbringing of girls from a young age leads to early pregnancy.

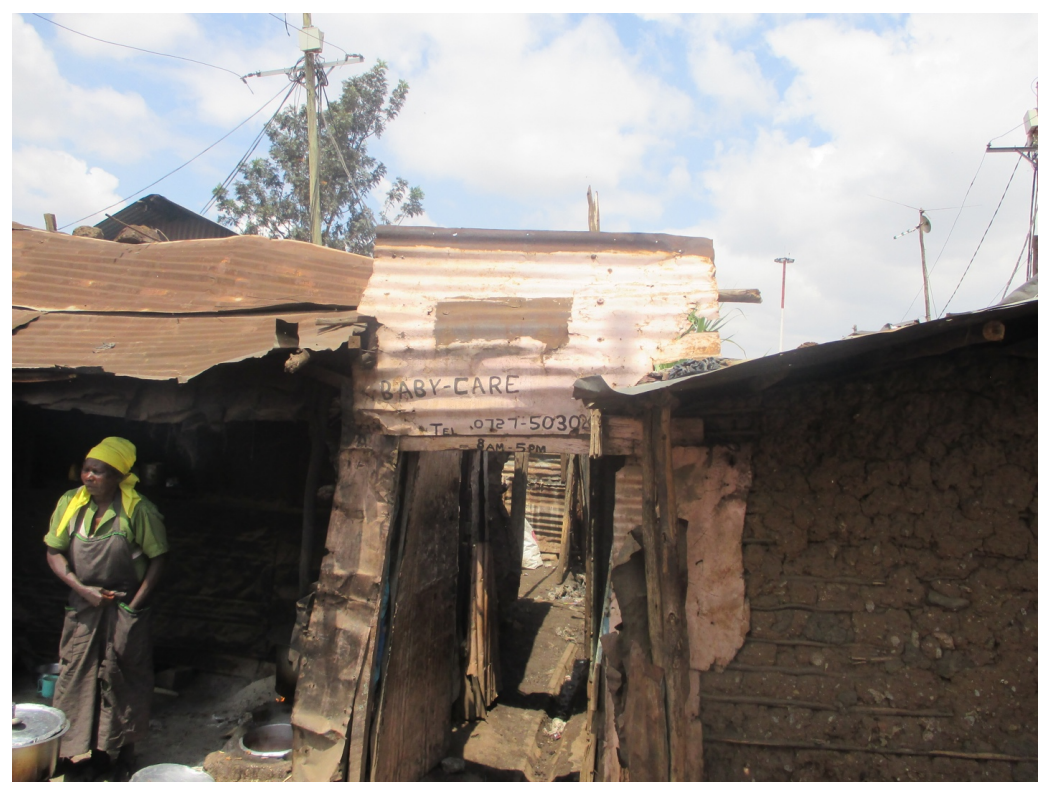

Figure 6. Young mothers lack the finances to pay for clean and reliable daycares.

Studies in Social Justice, Volume 12, Issue 2, 310-328, 2018 


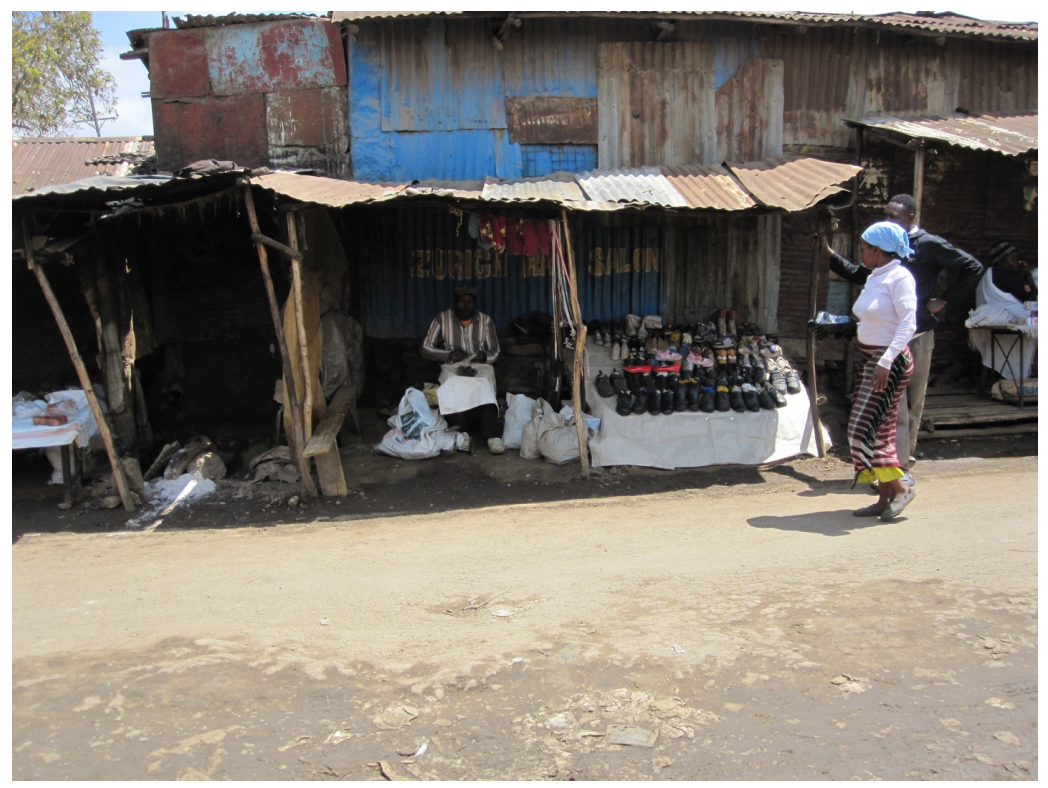

Figure 7. A teenage girl is looking for employment.

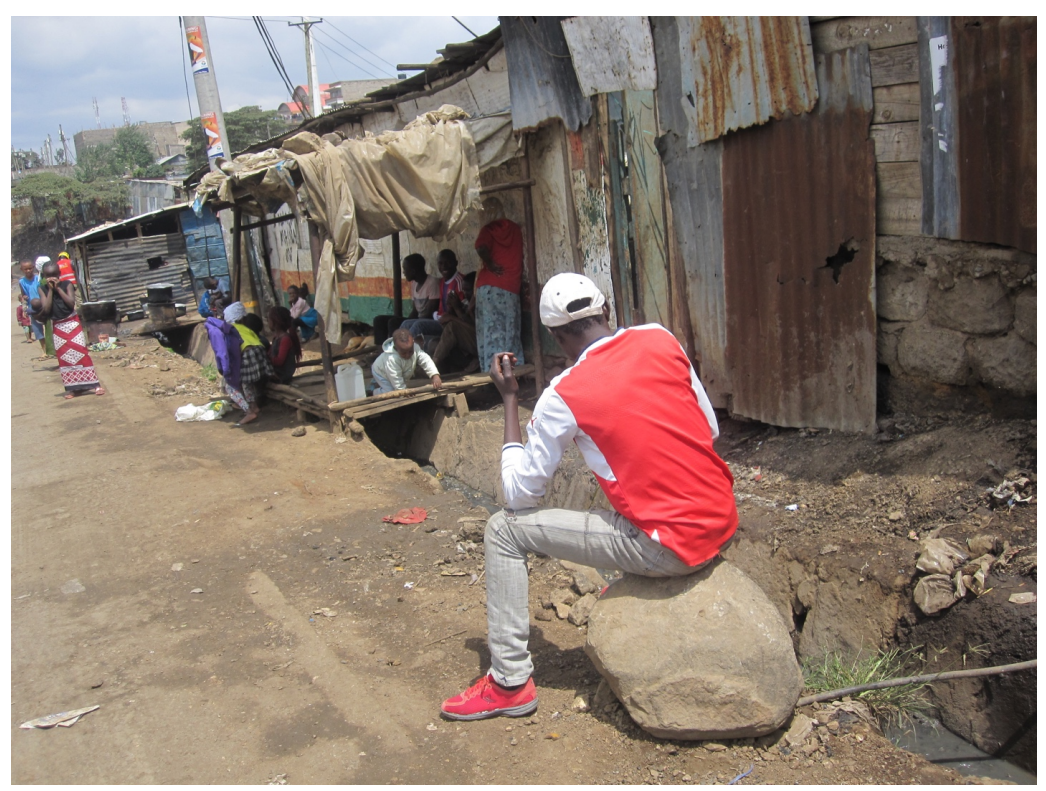

Figure 8 . Community members sitting by the roadside gossip about pregnant teenage mothers. 


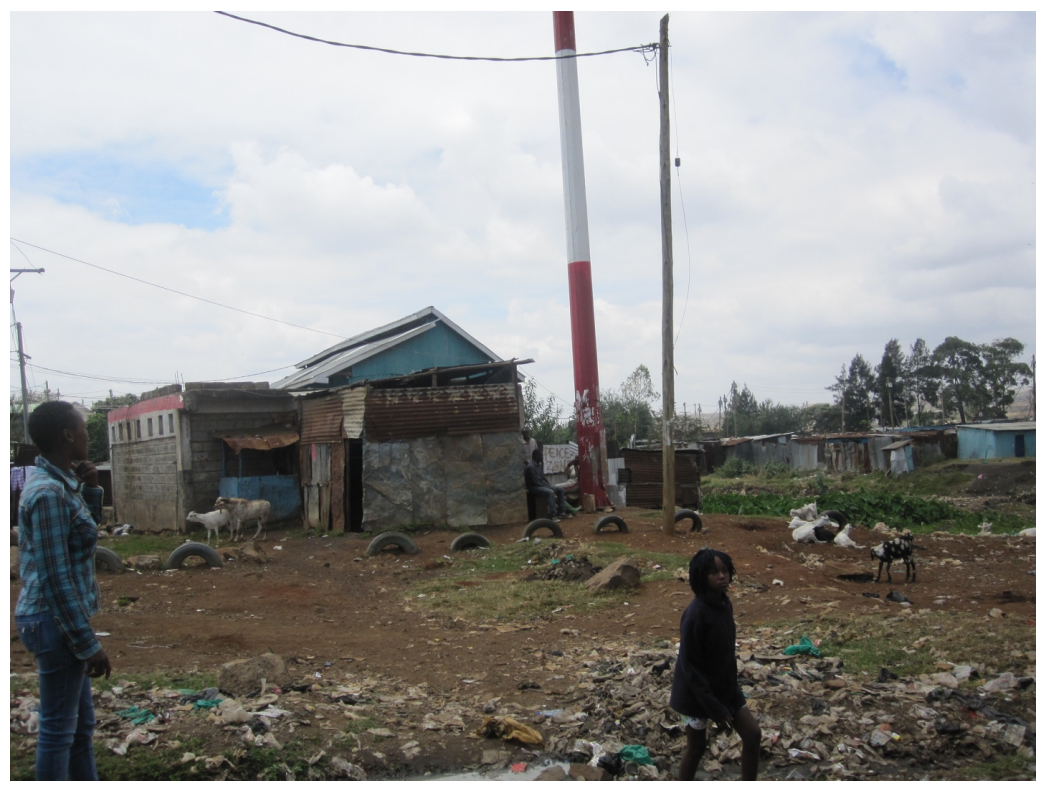

Figure 9. Young mothers looking for old plastic and metal at the dumpsite to re-sell for an income.

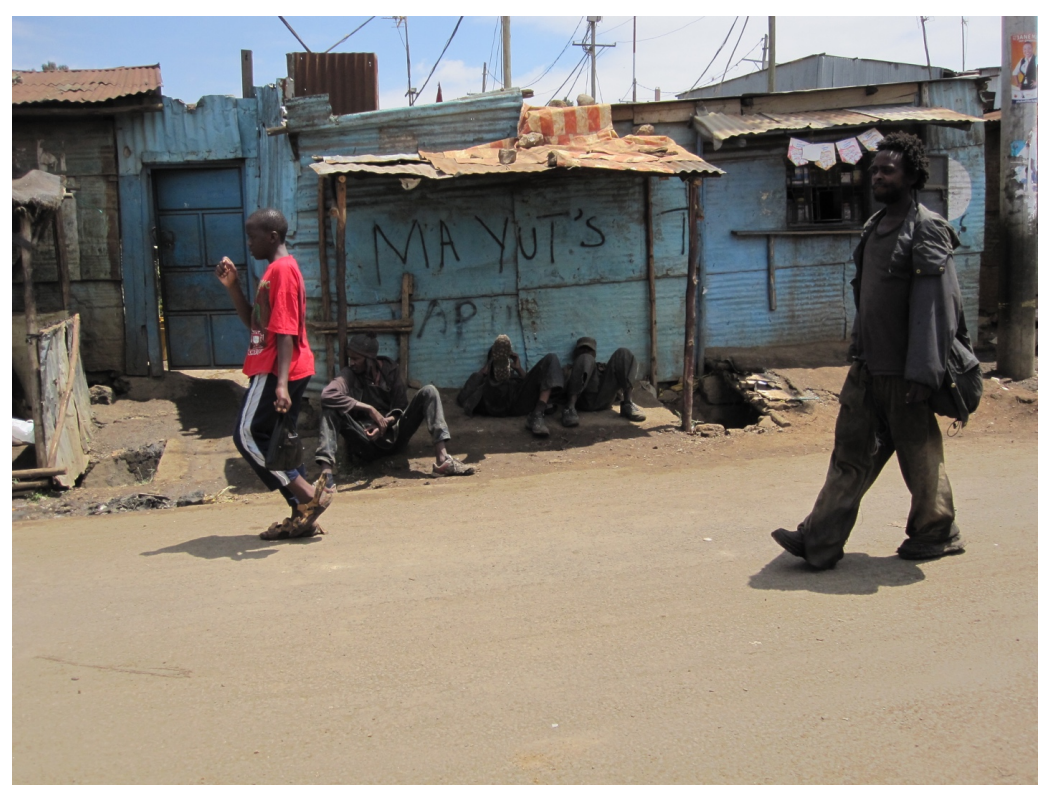

Figure 10. A state of hopelessness in the community. 


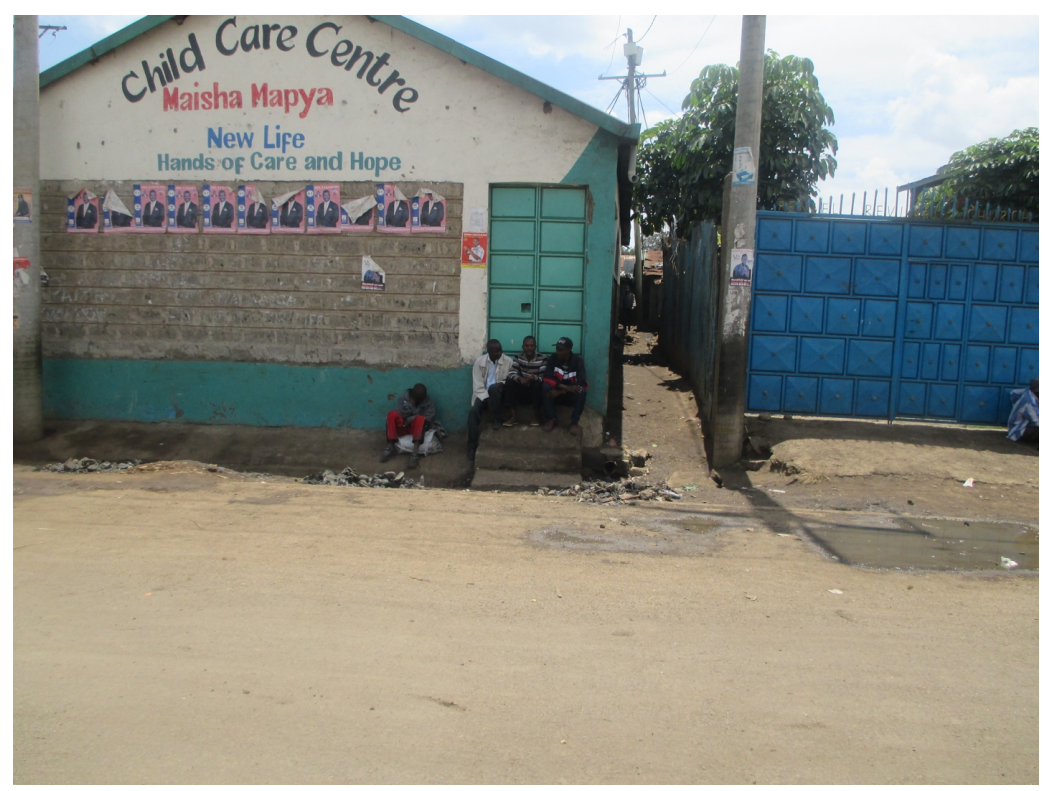

Figure 11. Lack of clean and efficient daycares.

\section{Using Photovoice to Re-Conceptualize School Re-Entry Policies for Young Mothers}

Most policy-making processes entail top-down technical approaches to policy formulation and design. Such approaches mean that only experts who are deemed to possess the requisite knowledge can identify problems and interventions for policy beneficiaries. Many well-intended policies fail to deliver their intended goals because of poor policy uptake due to mismatched need identification and interventions. The narratives about the challenges to schooling provided by the young mothers were curated and exhibited by the young mothers themselves to some selected audiences. The young mothers, in collaboration with the researcher, used the photovoice exhibition to engage the local community to raise awareness about some of the challenges faced by pregnant girls, young mothers, and policy-makers to encourage dialogue about policy. This approach reflects the work of De Lange, Mitchell and Moletsane (2015) with young women in South Africa to address sexual violence on university campuses, and their emphasis on using local knowledge and putting girls' voices at the center in formulating policies that affect their lives directly. In this study, the photovoice activity successfully exposed some of the barriers to schooling for young mothers in low-income contexts. This came from their depictions of their lived realities, which show the importance of girl-generated data and its potential to challenge the power 
dynamics. Through generating evidence themselves, girls and young women can positively influence the policy-making process.

The findings from the study highlight the following: (a) the intersecting challenges facing young mothers' school continuation and re-entry, (b) the need to incorporate girls and young mothers' voices and lived experiences in the formulation and design of robust school re-entry and continuation policies and interventions; and (c) the need to adopt a participatory approach to policy-making to address those issues. The policy literature provides a plethora of policy design frameworks, most of which are based on the conventional linear and top-down approaches. However, the multilayered and intersecting factors that cause marginalization of girls in education make it important to adopt intersectional and ground-up participatory approaches to policy formulation and design. Such approaches support the utility of feminist epistemologies such as feminist standpoint and perspectivism, and participatory visual approaches, as ways of re-conceptualizing effective policy-making (Acker, 1987; Rixecker, 1994). In their work with young women in South Africa, De Lange, Mitchell and Moletsane (2015) emphasize the importance of ground-up approaches and the value in locally constructed knowledge. Hankivsky and Cornier (2011) view an intersectional approach in designing education policies as an effective way to address gender inequality, as it acknowledges the layered and interlocking factors that work together to exclude or marginalize girls in education.

Feminist epistemological standpoint theory suggests that there are many social and "knowing" contexts, and therefore interrogates conventional concepts of knowledge creation by considering how female knowers might challenge dominant ways of knowing (Acker, 1987; Rixecker, 1994). Additionally, it cautions against both exploitation and silencing of women's "voices" in the research process. Rixecker (1994) acknowledges the absence of a feminist epistemological standpoint in most policy design and argues that this approach can expand the constructs of policy design and create a more inclusive and participatory approach to public policy design and analysis. Employing a feminist policy design allows for a re-conceptualization of the policy-making process by including a range of policy actors, including policy experts and intended policy beneficiaries, thereby expanding participation, increasing inclusivity, and being accommodative to alternative knowledge construction methods.

Policy-makers need to reform the normative process of policy formulation from a top-down approach to a ground-up approach where their policy decisions are based on the locally constructed knowledge drawn from the lived experiences of the intended policy beneficiaries. This calls for active participation of the beneficiaries - in this case pregnant girls and young mothers - in identifying the challenges to their school continuation and providing suggestions for possible mitigations. The photovoice project in this study demonstrates how voices of girls and young mothers can expose the daily struggles in their lives that act as barriers to their schooling and inform 
the identification of targeted intervention and policy reformulations that cater to their specific needs (King \& Winthrop, 2015). The learnings from this project will be shared with policy-makers in the form of an exhibition and exhibition catalogue to start a conversation on how to involve policy target populations, and specifically girls and young mothers in this study, in informing policy decision making on matters that concern their lives. This research project aims to mobilize the existing resources with the local community to garner support for the education of young mothers and to create awareness through sexual health education among youth in the community. The photo-narratives of challenges to young mother's education created by the young mothers will be shared with education stakeholders and policy-makers to discuss how to incorporate the voices of the young mothers in Korogocho, and those elsewhere in the country, in revising the school reentry and continuation policy.

Participatory visual methodologies are important tools to incorporate the voices and lived experiences of pregnant teenagers and young mothers in the school re-entry and continuation dialogue. Kirk's work (Kirk \& Garrow, 2003) forms the foundation of my central argument in this article. Her support for visual and other participatory approaches to generate knowledge from lived experiences of girls and female teachers in emergencies, and to convey policy messages for girls' education, is complemented by the photovoice study described in this article. The study with the young mothers advances Kirk's, which highlights the importance of employing multifaceted approaches to solving the issues of girls' education through collaboration between feminist scholars, educators, communities, activists, policy beneficiaries and policy-makers in conceptualizing effective educational policies and interventions. Kirk successfully combined academia, advocacy, and activism, demonstrating that a multi-pronged strategy is needed in order to provide a comprehensive solution for girls' education.

The use of participatory visual methodologies, such as photovoice, act as important tools to interrogate hierarchical and positivist paradigms in research, civic engagement, modes of representation and knowledge production (Mitchell \& Sommer, 2016; Weber, 2014). The participatory nature of photovoice, for example, calls for synergies and partnerships in policy designs from the initial problem identification phase, through to implementation and evaluation (Mitchell \& Sommer, 2016; Weber, 2014).

\section{Conclusion}

There is an urgent need for integrating feminist frameworks to promote systematic government educational policy reforms and evaluation, in order to achieve gender equality (King \& Winthrop, 2015). A broad conceptualization regarding the causes of teenage pregnancy, and prioritizing and centering the voices and lived realities of teenage girls, will deepen the understanding of 
ways economic, social, political, and cultural factors intersect to create barriers to schooling and challenges pregnant girls and young mothers in lowincome and marginalized contexts face. Unfortunately, economic, social, cultural and political factors intersect in interconnected ways to impede the schooling process of marginalized girls. Therefore, adopting a multi-pronged approach that combines a feminist epistemological standpoint and participatory visual methodologies to formulate education policies for marginalized girls in urban poor contexts who face an increased risk of discontinuing school is a valuable strategy. The use of participatory visual approaches like photovoice for research with girls and young women will help to make their voices heard in ways that make sense, are of significance to them, and empower them to become active in the policy processes where decisions are made that affect their lives. The participation of girls and young mothers in the policy formulation will democratize the process and enable the girls and young mothers to take ownership of the policies that directly affect their education.

Finally, in an article which is meant to pay tribute to the work of Kirk and her concern for the voices of girls and young women in policy dialogue, I want to end with a point about policy related to pregnancy and school continuation. The girls and young women offered many ideas about the barriers to their school continuation. I suggest that education policy-makers in low income countries should adopt a feminist framework and participatory approach. The current re-entry policies for young mothers in most low income countries need to be revised to be girl-centered and accommodate structures that would support the implementation of the revised policies as follows: (a) provide subsidized, clean and reliable daycares that young mothers would enroll their children as they attend school to facilitate their school re-entry and continuation; (b) include age appropriate comprehensive sexuality education and counselling in schools to promote healthy teenage sexuality and mitigate against unplanned teenage pregnancy that would act as challenges to teenage girls' schooling and; (c) provide conditional cash transfers for young mothers who return to school to subsidize their living expenses and that of their children. The three strategies suggested above when implemented together would offer a comprehensive intervention that would encourage young mothers to re-enroll and continue with their schooling. The strategies also offer preventive measures to reduce incidences of teenage pregnancy while also catering to the well-being of the children of the young mothers.

\section{Reference}

Arango, D. J., Morton, M., Gennari, F., Kiplesund, S., \& Ellsberg. M. (2014). Interventions to prevent or reduce violence against women and girls: A systematic review of reviews. (Women's Voice \& Agency Research Series 2014 No. 10: Gender Equality \& Development). Washington, DC: World Bank. Retrieved from 
www.worldbank.org/content/dam/Worldbank/document/Gender/Arango\%20et\%20al\%202 014.\%20Interventions $\% 20$ to $\% 20$ Prevent $\% 20$ or $\% 20$ Reduce $\% 20$ VAWG $\% 20$ $\% 20 \mathrm{~A} \% 20$ Systematic\%20Review\%20of\%20Reviews.pdf

Acker, S. (1987). Feminist theory and the study of gender. International Review of Education, 33(4), 419-435.

Beninger, C. (2013). Combating sexual violence in schools in sub-Saharan Africa: Legal strategies under regional and international human rights law. African Human Rights Law Journal, 13(2), 281-301.

Bhana, D. (2008). Discourses of childhood innocence in primary school HIV/AIDS education in South Africa. African Journal of AIDS research, 7(1), 149-158.

Bhana D., \& Mcambi, J. S. (2013). When schoolgirls become mothers: Reflections from a selected group of teenage girls in Durban. Perspectives in Education, 31(1), 11-19.

Bhana, D., Morrel, R., Shefer, T., \& Ngabaza, S. (2010). South African teachers' responses to teenage pregnancy and teenage mothers in schools. Culture, Health \& Sexuality, 12(8), 871-883.

Bobrow, D. B., \& Dryzek, J. S. (1987). Policy analysis by design. Pittsburg, PA: University of Pittsburgh Press.

Chilisa, B. (2002). National policies on pregnancy in education systems in sub-Saharan Africa: The case of Botswana. Gender \& Education, 14(2), 21-35.

De Lange, N., Mitchell, C., \& Moletsane, R. (2015). Girl-led strategies to address campus safety: Creating action briefs for dialogue with policy maker. Agenda, 29(3), 118-127.

(FAWE) Forum for African Women Educationalists. (2004). Annual report 2004. Nairobi, KE: FAWE. Retrieved from www.fawe.org/Files/fawe_annual_report_2004.pdf

Glick, P. (2008). What policies will reduce gender schooling gaps in developing countries: Evidence and interpretation. World Development, 36(9), 1646-1646.

Hankivsky, O., \& Cornier, R. (2011). Intersectionality and public policy: Some lessons from existing models. Policy \& Research Quarterly, 64(1), 217-229.

Kirk, J., \& Garrow, S. (2003). 'Girls in policy': Challenges for the education sector. Agenda, $17(56), 4-15$

King, E. M., \& Winthrop, R. (2015). Today's challenges in girls' education. (Global Economy and Development: Working Paper 90). Washington, DC: Brookings Institute. Retrieved from www.brookings.edu/wp-content/uploads/2016/07/Todays-Challenges-GirlsEducationv6.pdf

Leach, F., Dunne, M., \& Salvi, F. (2014). School-related gender-based violence: A global review of current issues and approaches in policy, programming and implementation responses to school-related gender-based violence ( $S R G B V)$ for the education sector. New York: UNESCO. Retrieved from https://hivhealthclearinghouse.unesco.org/sites/default/files/resources/schoolrelatedgenderb asedviolenceunescoglobalreviewjan2014.pdf

Lockheed, M. (2008). The double disadvantage of gender and social exclusion in education. In M. Tembon \& L. Fort (Eds.), Girls' education in the 21st century: Gender equality, empowerment, and economic growth (pp. 115-126). Washington, DC: International Bank for Reconstruction and Development/The World Bank.

Mashishi N., \& Makoelle, T. (2014). Inclusion or exclusion ramifications of teenage pregnancy: A comparative analysis of Namibia and South Africa school's pregnancy policies. Mediterranean Journal of Social Sciences, 5(14), 374-379.

Mitchell, C. M. (2011). Doing visual research. London: Sage.

Mitchell, C. M., \& Sommer, M. (2016). Participatory visual methodologies in global public health. Global Public Health, 11(5-6), 521-527.

Moletsane, R., Mitchell, C., \& Lewin, T. (2015). Gender equity as policy in South Africa: Privileging the voices of women and girls through participatory visual methods. In J. Parkes (Ed.), Gender violence in poverty contexts: The educational challenge (pp.183-196). New York: Routledge.

Mukudi, E. O. (2002). Gender and education in Africa. Comparative Education Review, 46(2), 234-241. 
Nyariro, M., Muthuri, S., Hani Sadati, S. M., Mitchell, C., \& Njeri, M. (2017). Picturing change through photovoice: Participatory evaluation of a daycare intervention in Kenya. GrOW Research Working Paper Series. Institute for the Study of International Development, McGill University, Montreal, Canada.

Onyango, G. O., Kioli, F. N., \& Nyambedha, E. O. (2015). Challenges of school re-entry among teenage mothers in primary schools in Muhoroni District, Western Kenya. SSRN Electronic Journal. Retrieved from http://dx.doi.org/10.2139/ssrn.2546761

Republic of South Africa. Government Gazette. (1996). South African School Act. Retrieved from www.gov.za/sites/www.gov.za/files/Act84of1996.pdf

Rixecker, S. S. (1994). Expanding the discursive context of policy design: A matter of feminist standpoint epistemology. Policy Science, 27(2-3), 119-142.

Sathiparsad, R., \& Taylor, M. (2011). Making meaning of teenage pregnancy among schoolgoing youth: The case of selected eTheKwini Municipality secondary schools. Agenda, 25(3), 72-84.

Schultz, T. P. (2002). Why governments should invest more to educate girls. World Development, $30(2), 207-225$.

Stromquist, N. P. (2003). Women's education in the twenty-first century: Balance and prospects. In R. F. Arnove \& C. A. Torres (Eds.), Comparative education: The dialectic of the global and the local ( $2^{\text {nd }}$ ed.) (pp. 176-203). Lanham, MD: Rowman \& Littlefield.

The Constitution of Kenya. (2010). Retrieved from www.wipo.int/edocs/lexdocs/laws/en/ke/ke019en.pdf

Undie, C., Birungi, H., Odwe, G., \& Obare, F. (2015a). Expanding access to secondary school education for teenage mothers in Kenya: A baseline study report. STEP UP Technical Report, Nairobi, KE.

Undie, C., Mackenzie, I., Birungi, H., Barongo, S., Ahindukha, D., \& Omondi, C. (2015b). Education sector response to early and unintended pregnancy: A policy dialogue in HomaBay County, Kenya. STEP UP Meeting Report, Nairobi, KE.

UNESCO. (2003). EFA global monitoring report. Gender and education for all: The leap to equality. New York: UNESCO.

Vandeyar, S., Dzimiri, P., Runhare, T., \& Mulaudzi, O. (2014). The non-alignment of espoused theories of action to theories-in-use: Sociocultural hurdles to provision of equitable educational opportunity for pregnant learners at South African conventional schools. Gender and Behaviour, 12(1), 6095-6112.

Weber, S. (2014). Arts-based self-study: Documenting the ripple effect. Perspectives in Education, 32(2), 8-20. 